\title{
SEND Developmental and Reproductive Toxicology Implementation Guide Version
} 1.1

National Cancer Institute

\section{Source}

National Cancer Institute. SEND Developmental and Reproductive Toxicology

Implementation Guide Version 1.1. NCI Thesaurus. Code C156616.

The 1.1 version of the standard for exchange of nonclinical data (SEND) developmental and reproductive toxicology (DART) implementation guide. 